\title{
The Cost-effectiveness of Lamotrigine in the Maintenance Treatment of Adults With Bipolar I Disorder
}

\author{
NEILL W. CALVERT, PhD; STEVEN P. BURCH, PhD; ALEX Z. FU, PhD; PENNY REEVES; and THOMAS R. THOMPSON, MD
}

\begin{abstract}
OBJECTIVE: To present an economic model and cost-effectiveness estimates for lamotrigine in maintenance treatment of bipolar I disorder (BD-I) using outcomes from the pivotal lamotrigine trials. The main comparator treatments in the pivotal trials were lithium and "no maintenance" (acute-only) treatment. A comparison with olanzapine was included as an indirect analysis following publication of data during the course of our research.

METHODS: A Markov model was built around the 3 health states of euthymia, mania, and depression. The base-case model simulates a cohort of 1,000 patients with BD-I who have recently stabilized after resolution of a bipolar mania episode. The cohort was modeled for a period of 18 months. Resource-use estimates were derived from best available published data, treatment guidelines, a physician survey, and published unit cost data. Outputs were measured in terms of costs per acute mood episode avoided, costs per euthymic day gained, and costs per quality-adjusted life-years (QALYs). Direct health care payer costs are used in the analyses.
\end{abstract}

RESULTS: The base-case model for patients with a recent manic episode indicated that lamotrigine is the most effective treatment for avoiding both acute depression episodes and all types of acute episodes (depression and mania). It is also the most effective treatment in terms of number of euthymic days achieved (309 days per patient per year). Olanzapine is most effective for avoiding acute mania episodes. Total direct costs of treatment are lowest for the lithium treatment arm (\$8,710 per patient for the 18 -month period). All maintenance therapies were cost effective compared with the no-maintenance (acute-only treatment) arm. In the base case, lamotrigine had incremental cost-effectiveness ratios of \$30 per euthymic day and $\$ 2,400$ per acute episode avoided compared with lithium. A QALY analysis indicated that lamotrigine is cost effective in patients with a recent manic episode at $\$ 26,000$ per QALY. The base-case model indicated that lamotrigine dominates olanzapine, (that is, lamotrigine costs less and is more effective than olanzapine) in patients with a recent manic episode. In a sensitivity analysis using outcomes from the pivotal trial of recently depressed patients, lamotrigine, in comparison with lithium, was not shown to be as cost effective as in the recently manic patients, but it was still cost effective compared with no maintenance treatment.

CONCLUSIONS: For a defined cohort of patients with BD-I, the pharmacoeconomic model indicated that prevention of mood episodes with lithium and lamotrigine is cost effective in patients with a recent manic, mixed, or hypomanic episode. The conclusions with respect to the indirect comparison with olanzapine should be validated if and when direct trial data become available. Cost-effectiveness of maintenance treatments for patients with BD-I (recently depressed as well as recently manic) are likely to improve in models with a broader costing perspective and that take a longer time frame. Further research into the outcome implications of health-related quality of life and other BD subgroups are recommended.

KEYWORDS: Modeling, Cost-effectiveness, Bipolar, Maintenance treatment

J Manag Care Pharm. 2006;12(4):322-30
$\mathrm{B}$ ipolar disorder (BD) is a psychiatric disorder characterized by recurrent mood episodes. In the most common manifestation of the disease, bipolar I disorder (BD-I), the patient's mood alters between periods of euphoria, restlessness, poor judgment, and risk-taking behavior (manic episodes); periods of depression, anxiety, and hopelessness (depressive episodes); and periods of euthymia (normal mood).

Management of BD usually involves a combination of drug treatment, psychotherapy, and social support. For patients experiencing an acute mood event, the goal of treatment is to normalize the patient's mood and help the patient resume normal functioning, while minimizing risk to the patient. The goal of medication therapy of patients in the euthymic state is to maintain euthymia for as long as possible and to reduce the patient's risk of experiencing another acute mood episode. In maintenance treatment, lithium has been generally accepted as a first-line therapy, ${ }^{1}$ although the evidence base for its effectiveness has until recently been incomplete. There is increasing evidence that newer agents, in particular anticonvulsants and atypical antipsychotics, have a potentially important role to play in the management of $\mathrm{BD} .^{2 \cdot 4}$

The U.S. prevalence of $\mathrm{BD}$ has been estimated at $2 \%$, affecting both men and women equally. ${ }^{5}$ Relatively new epidemiologic data expand the concept of $\mathrm{BD}$ to include subthreshold expressions of mania, hypomania, brief hypomania, and cyclothymia. These studies suggest a higher prevalence of up to $5 \%$ of $\mathrm{BD} .{ }^{6-10}$ The burden of illness for BD in the United States has been estimated at $\$ 45$ billion, ${ }^{11}$ with a more recent estimate of $\$ 24$ billion for the lifetime costs for bipolar patients. ${ }^{12}$

Given the considerable resource burden of $\mathrm{BD}$, it was surprising that, at the time our work started, there was no

\section{Authors}

NEILL W. CALVERT, PhD, is senior health economist and PENNY REEVES is a health economist, Fourth Hurdle Consulting, London, UK; STEVEN P. BURCH, PhD, is manager, USP Health Outcomes, and THOMAS R. THOMPSON, MD, is director, Neurosciences MDC, U.S.Clinical, GlaxoSmithKline Research Triangle Park, North Carolina; ALEX Z. FU, $\mathrm{PhD}$, is an assistant professor, Department of Quantitative Health Sciences, Cleveland Clinic Foundation, Cleveland, Ohio.

AUTHOR CORRESPONDENCE: Neill Calvert, PhD, Senior Health Economist, Fourth Hurdle Consulting Ltd., Holborn Tower, 137-144 High Holborn, London WC1V 6PL, UK. Tel: +44(0)20 7440 4074; Fax: +44(0)207440 4070; E-mail: NeillCalvert@fourthhurdle.com Copyright $\odot$ 2006, Academy of Managed Care Pharmacy. All rights reserved. 
TABLE 1 Schematic Representation of the Quarterly Model Structure

\begin{tabular}{|c|c|c|c|}
\hline & Bowden $^{13}$ & Calabrese $^{14}$ & Tohen $^{15,16}$ \\
\hline Randomized & Yes & Yes & Yes \\
\hline Blinded & Double-blinded & Double-blinded & Double-blinded \\
\hline Placebo-controlled & Yes & Yes & Yes \\
\hline Patient inclusion criteria & $\begin{array}{l}\text { Bipolar I patients aged } \geq 18 \text { years. } \\
\text { Had a diagnosis of bipolar I disorder, } \\
\text { most recent episode manic or hypo- } \\
\text { manic as determined by DSM-IV, or } \\
\text { had a manic/hypomanic episode either } \\
\text { currently or within } 60 \text { days prior to } \\
\text { screening, and had at least } 1 \text { manic/ } \\
\text { hypomanic episode and } 1 \text { depression } \\
\text { episode within the previous } 3 \text { years }\end{array}$ & $\begin{array}{l}\text { Bipolar I patients aged } \geq 18 \text { years } \\
\text { Had a diagnosis of bipolar I disorder, } \\
\text { most recent episode depressed, as } \\
\text { defined by DSM-IV criteria, either } \\
\text { currently or within } 60 \text { days prior to } \\
\text { the screening visit, and had at least } \\
1 \text { manic or hypomanic episode and } \\
1 \text { depression episode within the } \\
\text { previous } 3 \text { years }\end{array}$ & $\begin{array}{l}\text { Bipolar I patients aged } \geq 18 \text { years } \\
\text { Index manic or mixed as determined } \\
\text { by DSM-IV and a Young mania rating } \\
\text { Score } \geq 20 \text { and at least } 2 \text { manic or } \\
\text { mixed episodes in previous } 6 \text { years }\end{array}$ \\
\hline Primary outcome measure & $\begin{array}{l}\text { Time to intervention (addition of } \\
\text { pharmacotherapy or ECT) for any } \\
\text { mood episode }\end{array}$ & $\begin{array}{l}\text { Time to intervention (addition of } \\
\text { pharmacotherapy or ECT) for any } \\
\text { mood episode }\end{array}$ & $\begin{array}{l}\text { Time to symptomatic relapse to, or } \\
\text { hospitalization for, any mood episode }\end{array}$ \\
\hline Study follow-up & Up to 18 months & Up to 18 months & Up to 48 weeks \\
\hline
\end{tabular}

DSM-IV= Diagnostic and Statistical Manual of Mental Disorders, Fourth Edition; ECT=electro-convulsive therapy.

evidence regarding the cost-effectiveness of bipolar maintenance treatments. This article reports the results of a modeling exercise designed primarily to derive estimates of the cost-effectiveness of lamotrigine and lithium. The research was commissioned by the manufacturers of lamotrigine, who wanted to explore the cost-effectiveness of their product using outcomes results of their pivotal trials. ${ }^{13,14}$

These double-blind, placebo-controlled trials were conducted to meet the requirements of the U.S. Food and Drug Administration for approval of lamotrigine (Lamictal) as maintenance treatment in BD-I. The studies were conducted to assess the efficacy and tolerability of lamotrigine and lithium compared with placebo for the prevention of relapse or recurrence of mood episodes in recently (within 60 days of screening) manic or hypomanic patients (Bowden et al. ${ }^{13}$ ), and in currently or recently depressed (Calabrese et al. ${ }^{14}$ ) patients, respectively. The primary outcome measure was time from randomization to intervention (addition of pharmacotherapy or electroconvulsive therapy) for any current or emerging mood episode (depressive, manic, hypomanic, or mixed).

Although the original objective of this research was to assess the cost-effectiveness of lamotrigine pivotal trial drugs alone, new data regarding the effectiveness of olanzapine became available during the course of our research. ${ }^{15}$ This research has recently been published. ${ }^{16}$ The olanzapine study used similar patients and outcome measures to the Bowden trial (bipolar patients with a recent manic episode). A summary of the trial designs, patient inclusion criteria, and primary outcome measures used in the 3 trials are summarized in Table 1. In light of this development, we refocused the economic appraisal on to

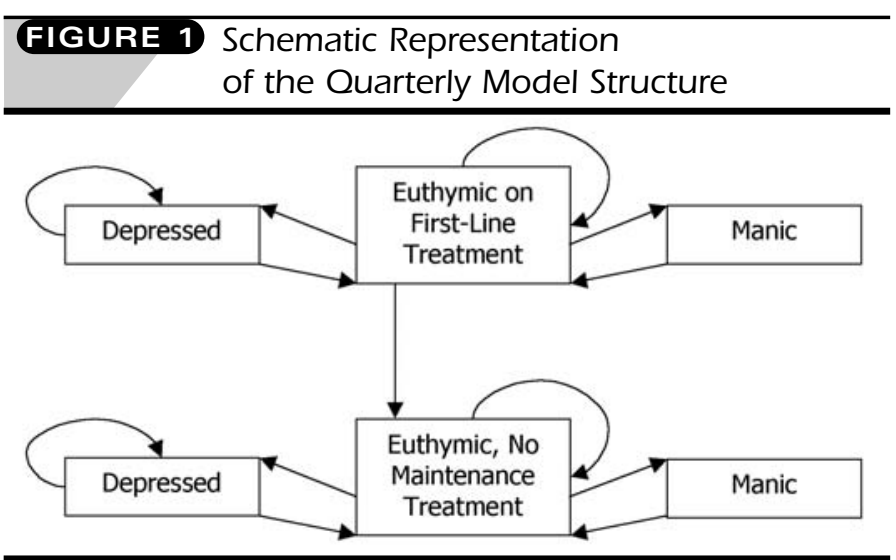

the recently manic subpopulation from Bowden's trial, which is appended with an analysis using an indirect comparison with olanzapine. In a sensitivity analysis, we investigated the effects of substituting the outcomes data from Bowden's trial of recently manic bipolar patients with those from Calabrese's trial of recently depressed patients.

\section{Methods}

The 3 treatment options originally included in our model were those from the pivotal trials for lamotrigine, namely

1. lamotrigine monotherapy,

2. lithium monotherapy, and

3. acute treatment only (placebo) therapy.

As discussed above, a supplementary economic evaluation of olanzapine monotherapy (using an average dose of $12.5 \mathrm{mg}$ 


\begin{tabular}{|c|c|c|c|c|}
\hline Quarterly Transitional Probability & No Maintenance Treatment & Lithium & Lamotrigine & Olanzapine \\
\hline$P$ (depressed in a given quarter) & 0.408 & 0.143 & 0.071 & 0.168 \\
\hline$P$ (adverse event or withdrew consent) & - & 0.185 & 0.059 & 0.099 \\
\hline
\end{tabular}

\begin{tabular}{|c|c|c|}
\hline Resource Variable & $\begin{array}{c}\text { Unit } \\
\text { Resource/Cost }\end{array}$ & Source \\
\hline \multicolumn{3}{|l|}{ Maintenance treatment } \\
\hline amotrigine $200 \mathrm{mg}$ daily & $\$ 3.51$ & Red Book 2004 \\
\hline ithium 900 mg daily & $\$ 0.53$ & Red Book 2004 \\
\hline Dlanzapine $12.5 \mathrm{mg}$ daily & $\$ 12.47$ & Red Book 2004 \\
\hline lithium tests per annum & $\$ 49.92$ & Medicare C LAB* \\
\hline hysician time per hour & $\$ 170.63$ & $\begin{array}{c}\text { Medicare } \\
\text { RBRVS 2004† }\end{array}$ \\
\hline $\begin{array}{l}\text { Average physician monitoring time } \\
\text { per month }\end{array}$ & 11.25 minutes & Physician survey \\
\hline \multicolumn{3}{|l|}{ Costs of acute bipolar mania } \\
\hline $\begin{array}{l}\text { Average duration of bipolar manic } \\
\text { episode }\end{array}$ & 30 days & Physician survey \\
\hline $\begin{array}{l}\text { Antimanic drugs } \\
\text { ( } 750 \mathrm{mg} \text { valproate daily ) }\end{array}$ & $\$ 3.27$ & Red Book 2004 \\
\hline$\%$ of manic patients hospitalized & $44 \%$ & Physician survey \\
\hline Average days hospitalized (mania) & 11.3 days & 2002 H-CUP $\ddagger$ \\
\hline Average cost per inpatient bed day & $\$ 934$ & 2002 H-CUP \\
\hline $\begin{array}{l}\text { Average physician monitoring time } \\
\text { per month }\end{array}$ & 72.5 minutes & Physician survey \\
\hline \multicolumn{3}{|l|}{ Costs of acute bipolar depression } \\
\hline $\begin{array}{l}\text { Average duration of bipolar depressive } \\
\text { pisode }\end{array}$ & 75 days & Physician survey \\
\hline $\begin{array}{l}\text { Anti depression drugs } \\
30 \text { mg paroxetine daily) }\end{array}$ & $\$ 2.90$ & Red Book 2004 \\
\hline$\%$ of depressive patients hospitalized & $18 \%$ & Physician survey \\
\hline Average days hospitalized (depression) & 8.3 days & 2002 H-CUP \\
\hline Average cost per inpatient bed day & $\$ 628$ & 2002 H-CUP \\
\hline $\begin{array}{l}\text { Average physician monitoring time } \\
\text { per month }\end{array}$ & 28.8 minutes & Physician survey \\
\hline
\end{tabular}

* CMS file CLAB2004. (Available at: http://www.cms.hhs.gov/providers/ pufdownload/default.asp\#labfee. Accessed August 21, 2004.)

† CMS file PPRRVU04.xls. (Available at: http://www.cms.hhs.gov/providers/

pufdownload/default.asp. Accessed August 21, 2004.)

\# Healthcare Cost and Utilization Project. AHRQ. (Available at:

http://hcup.ahrq.gov/HCUPnet.asp. Accessed August 21, 2004.)

RBRVS=Resource-Based Relative Value System. per day, derived from using outcome data from results presented by $T_{0 h e n^{15,16}}$, was added during the course of our research.

\section{Model Structure}

A schematic representation of the model structure is given in Figure 1. Patients enter the model once their illness has been stabilized and they are initially assigned to the euthymic health state.

In subsequent time periods, the model assumes that patients either remain euthymic or transition either to acute depression or mania health states. Patients entering the acute health states remain in that state for a period of time determined by the average length of the acute episode.

Unlike the pivotal trials, where patients were usually withdrawn once they had experienced an acute bipolar episode, our model retains the patient in the health care system as per the real world. One modeling simplification that we made was to assume that patients experiencing an acute bipolar episode transition back to the euthymic state before they experience a second or subsequent acute episode. The trial data indicated that some patients autonomously discontinue maintenance treatment. Discontinuation is facilitated in the model structure by allowing patients to switch from the maintenance treatment arm into a "no-maintenance" (placebo) arm.

Markov models are frequently used to evaluate clinical scenarios where patients can transition between defined health states during any of the defined transition periods. The Markov structure makes the assumption that the transition probabilities remain constant for each of the transition periods. We thus adopted a Markov model structure with a time span of 18 months, determined by the length of the lamotrigine trials, but divided into 6 quarterly transition periods.

\section{Populating the Model}

We populated the base-case model with a theoretical cohort of 1,000 patients deemed to have stabilized following a mixed/manic BD-I episode. That is, our base-case patients are similar to the patients included in the Bowden trial. ${ }^{13}$

\section{Transitional Probabilities}

The trials recorded the time to intervention for the first event 
(manic, hypomanic, mixed, or depressive episode) and the number of patients completing the 18 months free of intervention for an actual or emerging mood episode (completers). These event probabilities were used to derive the quarterly transitional probabilities used in the model. The placebo outcomes were used as a proxy for the no-maintenance treatment group in our model. Data from patients who withdrew from the study due to an adverse event or consent withdrawal were used to represent patients who stop maintenance therapy and transition to the no-maintenance therapy state.

In line with Markov modeling principles, the transitional probabilities were assumed to be equal over the 6 quarterly time periods of the model. For example, for a given treatment option, if $\mathrm{X} \%$ of patients completed after 18 months, then the quarterly probability of being event free in a given quarter was estimated as X(1/6) The residual probability was then assigned across the other events in proportion to the size of the 18-month event risks.

We derived transitional probabilities for olanzapine using Tohen's ${ }^{15}$ reported outcomes and anchoring to Bowden outcomes using the placebo results from these 2 trials. In brief, we estimated the risks ratios of modeled events for patients receiving olanzapine compared with the placebo group. In an attempt to allow for differences in patient populations in the 2 trials, these risk ratios were then multiplied by the absolute placebo rates from Bowden. Because the placebo rate for completers was zero in Bowden, we arbitrarily assumed that there was 1completer to enable us to estimate a completer rate for olanzapine. The resulting risk probabilities for olanzapine were then converted to constant Markov quarterly transitional probabilities in the same way as for lithium and lamotrigine. The resulting modeled transitional probabilities are given in Table 2 .

\section{Resource-Use Estimates}

The model takes a direct-payer costing perspective (year 2004 US\$). Modeled resource-use items include drug costs for maintenance treatment, drug and hospitalization costs for the treatment of acute manic and depressive episodes, and costs of associated contacts with health care professionals for monitoring and pathology tests. In brief, patients experiencing an acute episode were assumed to remain on maintenance treatment in addition to any newly added acute treatments (valproate for mania and paroxetine for depression). A proportion of these patients are assumed to require inpatient care.

All the resource-use assumptions, unit costs, and data sources are presented in Table 3. Unit costs were obtained from common sources such as drug prices from the Red Book. The length of acute episodes, the proportion of patients hospitalized, and physician monitoring time were estimated using responses from a physician survey. The objective of the survey was to assess BD knowledge, attitudes, and practice patterns of psychiatrists and primary care providers from a large, vertically

\begin{tabular}{|c|c|c|c|c|}
\hline & Lamotrigine & Lithium & Placebo & Olanzapine \\
\hline Mania episodes & 1,418 & 1,313 & 2,644 & 1,030 \\
\hline (PPPY) & $(0.95)$ & $(0.88)$ & $(1.76)$ & $(0.69)$ \\
\hline Depression episodes & 598 & 1,140 & 1,822 & 1,080 \\
\hline (PPPY) & $(0.4)$ & $(0.76)$ & $(1.21)$ & $(0.72)$ \\
\hline Total acute episodes & 2,016 & 2,453 & 4,466 & 2,110 \\
\hline (PPPY) & (1.34) & (1.64) & $(2.98)$ & $(1.41)$ \\
\hline Direct total costs & $\$ 9,755,052$ & $\$ 8,709,608$ & $\$ 16,083,654$ & $\$ 11,092,542$ \\
\hline (PPPY) & $(\$ 6,503)$ & $(\$ 5,806)$ & $(\$ 10,722)$ & $(\$ 7,395)$ \\
\hline Days in euthymic state & 463,789 & 429,313 & 339,986 & 441,485 \\
\hline (PPPY ) & (309) & (286) & (227) & (294) \\
\hline Days in manic state & 42,549 & 39,386 & 79,320 & 30,900 \\
\hline (PPPY) & (28) & (26) & (53) & (21) \\
\hline Days in depression state & 41,162 & 78,801 & 128,193 & 75,115 \\
\hline (PPPY) & (27) & (53) & (85) & (50) \\
\hline$\overline{\text { QALYS }}$ & 1,143 & 1,103 & 1,038 & 1,109 \\
\hline (PPPY ) & $(0.762)$ & $(0.735)$ & $(0.692)$ & $(0.739)$ \\
\hline
\end{tabular}

integrated health system in the Midwest. In order to fill in some of the data gaps for populating our model, we appended some targeted questions to the psychiatrist survey. Other results from the original survey are to be published shortly. ${ }^{17}$ All of these resource-use assumptions are tested in sensitivity analyses.

\section{Health-State Utilities}

Health-state utility values were estimated using a standard algorithm, ${ }^{18}$ and the 36-item short form (SF-36) values were collated as part of the lamotrigine pivotal trials and supplemented with values from published literature. ${ }^{19}$ Consequently, our analysis assumed utility values of $0.8,0.7$, and 0.4 for euthymic, manic, and depressive mood states, respectively. Key outcomes estimated by the model for each treatment arm included the number of acute episodes, the number of euthymic days, direct health care costs, and QALYs.

\section{Results}

Table 4 presents the results of modeling the 3 baseline treatment options and olanzapine monotherapy using effectiveness data from pivotal trials including patients with a recent episode of mania or hypomania. Over the 18-month period analyzed, and for the 1,000 patient cohort, the model indicated that treatment with lithium monotherapy was the least-costly treatment option in terms of total direct costs. The no-maintenance treatment option was the highest direct-cost option, due to more hospitalizations. In common with previously published burden of disease analyses, ${ }^{20-22}$ our model indicated that the majority of $\mathrm{BD}$ 


\section{FIGURE 2 Cost-effectiveness Frontiers}
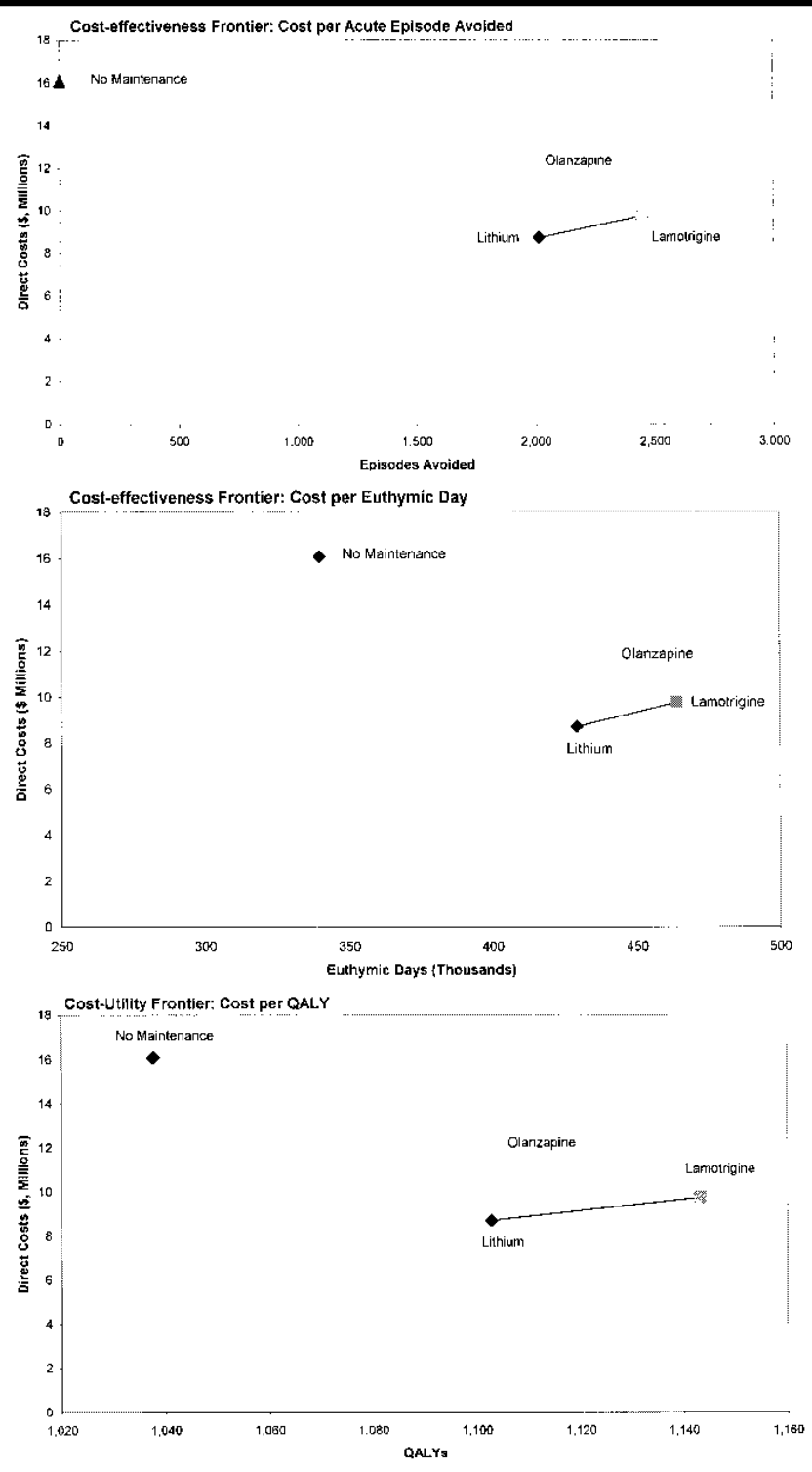

QALY= quality-adjusted life-year.

direct costs are hospitalization costs. For patients with recent manic episodes, the model indicated that lamotrigine may save hospital resources compared with lithium, through reduced admissions for depressive episodes.

Lamotrigine monotherapy resulted in the fewest depressive episodes, achieved the most euthymic days, and gained the most QALYs of all 4 treatment options. Olanzapine avoided the most acute manic episodes in the model. All of the active treatment regimes dominated the no-maintenance treatment option for all 3 measures of effectiveness (Figure 2). That is, maintenance treatments were less costly and more effective.
Lamotrigine also dominated olanzapine for all 3 measures of effectiveness using this model. The incremental cost-effectiveness of lamotrigine compared with lithium was $\$ 2,400$ per episode avoided, $\$ 30$ per euthymic day gained, and $\$ 26,000$ per QALY. Compared with lithium, we estimated olanzapine incremental cost-effectiveness ratios (ICERs) of $\$ 200$ per euthymic day gained, $\$ 7,000$ per acute episode avoided, and $\$ 374,500$ per QALY.

\section{Sensitivity Analysis}

In order to test the sensitivity of our model outputs to the input assumptions, we undertook a comprehensive set of sensitivity analyses, including 1- and 2-way sensitivity analyses, threshold, and scenario analyses.

Table 5 presents the proportional change in euthymic day and cost outcome variables for lamotrigine as well as the incremental cost per euthymic day (lamotrigine compared with lithium), which results from having changed lamotrigine input variables by $10 \%$.

The model outputs were most responsive to the transitional risk probabilities. A $10 \%$ increase in the lamotrigine mania quarterly transitional probability produced a $66 \%$ increase ( $\$ 30.30$ to $\$ 50.00$ ) in the value of the euthymic day ICER. Although changing the price of lamotrigine itself had a relatively small impact on direct cost outcomes, it had a proportionate effect on the ICER. Other variables that had a greater relative influence on direct costs (e.g., inpatient costs for mania) had a relatively small effect on the ICER because lithium patients experiencing mania also incurred these increased costs.

One-way sensitivity analyses to assess the sensitivity of the lithium-lamotrigine QALY ICER to a 10\% change (increase) in the 3 health-state utility values, were also undertaken. The results showed a relatively sensitive (16\%) improvement in the ICER from changing the euthymic utility in contrast to a relatively insensitive (1.5\%) improvement resulting from changing the mania utility. There was a proportionate change in the ICER resulting from the $10 \%$ change in the depression utility.

A threshold analysis that sought out a dominant solution for lamotrigine over lithium required large changes in input assumptions. For some variables, including those associated with the use of a mania-related hospitalization resource, a dominant solution was not possible. The most responsive variable was the mania risk transitional probability for lamotrigine. Lamotrigine dominated lithium if the value of the mania risk transitional probability changed to a value of 0.172 from the base-case value of 0.215 .

Our base-case model used effectiveness data from the Bowden trial (bipolar patients with a recent bipolar mania episode). ${ }^{13}$ We undertook a sensitivity analysis in which we replaced the effectiveness data with that from the Calabrese trial (bipolar patients with a recent depressive episode). ${ }^{14}$ Olanzapine was excluded from this subanalysis because there 
lamotrigine costs less and is more effective than olanzapine. These findings are the result of an indirect comparison using outcomes from the Bowden ${ }^{13}$ and the Tohen ${ }^{15,16}$ trials. In the absence of head-to-head trial data, it is legitimate practice in economic evaluations to use modeling techniques to make indirect comparisons (as frequently demonstrated by NICE and the SMC in the United Kingdom). However, the validity of our findings is dependent on the validity of our indirect comparison. We believe that the similarity of the Bowden and the Tohen study designs, and their patient inclusion criteria (Table 1), support our decision to add olanzapine to our-base case analysis.

Sensitivity analyses indicated that key results were insensitive to variables that can be described as having a right-skewed distribution, including length of acute episode and length of hospital stay. The modeled ICERs were, however, sensitive to input variables that independently affect outcomes for individual treatment options such as the cost of maintenance treatments. The ICERs were most sensitive to inputs that increased the numerator (incremental costs) and simultaneously decreased the denominator (incremental effectiveness), or vice versa. As such, the ICERs were relatively sensitive to changes in transitional probability values.

With this in mind, it should be noted that the Markov transitional probabilities for lamotrigine, lithium, and the no-maintenance treatment arms were estimated using the 18-month event rates in the 2 lamotrigine pivotal trials. The event rates were assumed to decline exponentially from time zero to 18 months. In fact, the Kaplan-Meier curves indicate that avoidance of events was relatively good up to 12 months but declined between 12 and 18 months. As such, our exponential decline assumption may underestimate the 12-month survival rates for lithium and lamotrigine, and particulary so for the no-maintenance treatment arm in the base-case model, since no placebo patients in the Bowden trial survived to 18 months. Furthermore, the olanzapine trial only had a 12-month follow-up period, so the transitional probabilities for olanzapine were estimated from the 12-month "survival" data reported by Tohen et al. It may be that our analysis is therefore biased against lamotrigine and lithium.

Replacing the effectiveness data from the Bowden trial (recently manic patients) with that from the Calabrese trial (recently depressed patients) ${ }^{14}$ produced less-optimistic economic messages for lamotrigine. This may seem counterintuitive, given lamotrigine's efficacy against bipolar depression, but it can be explained by the following:

- patients with a recent manic episode have a greater tendency to relapse to the manic pole, while patients recently depressed tend to relapse to the depressive pole ${ }^{25,26}$;

- the pivotal trial data also indicate that patients in the recently manic trial experienced more acute episodes than patients in the recently depressed trial;

- the average cost of a manic episode is greater than that of a depressive episode primarily because a greater proportion of patients are hospitalized during a manic episode; and

- manic episodes are, on average, shorter than depression episodes.

The combined effect of the above in our 18-month model is that there is reduced opportunity for avoidance of acute events in patients with a recent depression episode, with poorer health and cost consequences for this patient subgroup compared with that available to patients with recent mania as presented in the base-case model.

In order to undertake a QALY analysis, we needed to make assumptions about the health utility values for patients experiencing euthymic, depression, and mania health states. Because of the potential difficulties of eliciting utility values for patients experiencing mania, ${ }^{27}$ further research in this area of healthstate valuation would be helpful to inform future cost-utility (QALY) analysis. ${ }^{28}$

\section{Limitations}

The limitations of our study are determined largely by the simplifying assumptions that were made in constructing and populating the model. The validity of model results is restricted to the subgroup of patients with $\mathrm{BD}$ included in the pivotal clinical trials. The results should not be interpreted as being relevant to patients excluded from the trials, for example, rapid cyclers.

We believe the indirect comparison with olanzapine is a valid one both methodologically and because of the similarities between the Bowden and the Tohen trials. Having said this, we acknowledge that the ideal would be a well-designed randomized head-to-head trial of competing maintenance treatments. The outcomes of such a trial could then be used to derive transitional probabilities, which could be fed into our model in order to test the robustness of our current findings. Until such time, we argue that our model outcomes can be supported as currently best available evidence.

The 18-month time frame of our model was driven by the 18-month time frame of the pivotal clinical trials. However, BD is a chronic disease with a relatively young age of onset. We alluded to the fact that a longer time frame model may be necessary in order to demonstrate the economic advantages of maintenance treatments in patients with a recent bipolar depression episode. Also, the current model does not consider the disutility and costs of long-term adverse medication events. The well-tolerated side-effect profile of maintenance treatments, such as lamotrigine, may well mean that inclusion of such events in a longer time frame model will favor some maintenance treatments in comparison to lithium.

As discussed above, our model takes a direct-payer costing perspective. Broadening the costing perspective to include patient and caregiver costs, indirect costs to the economy through time lost from work, and the cost implications for the 
criminal justice system and substance abuse services is likely further to improve the pharmacoeconomics of maintenance therapies that avoid acute episodes of bipolar depression and mania.

\section{Conclusions}

ICERs are an appropriate outcome variable for efficiency decision making in health economic evaluation. ${ }^{29,30}$ To date, few economic studies in BD have presented ICERs. ${ }^{20,27,31-33}$ In light of this, we constructed an economic model that generated ICERs for lamotrigine, lithium, and no-maintenance treatment using pivotal trial data, and have made an indirect comparison with olanzapine. Our model indicates that lithium and lamotrigine are cost effective in patients with a recent episode of mania.

We have presented the assumptions that were used to structure and populate our model and have indicated where the outputs are sensitive to such assumptions. We also highlighted potential limitations of our approach and acknowledge their significance. Despite the limitations, we feel this study has resulted in useful and informative economic data in an under-researched area.

We believe that our economic model of maintenance treatments for BD-I provides a good baseline on which future models can be developed. We recommend that future models should consider inclusion of a longer time perspective and a broader costing perspective. We believe that such models are likely to provide even more optimistic cost-effectiveness outputs for maintenance treatments in BD.

\section{DISCLOSURES}

Funding for this research was provided by GlaxoSmithKline (GSK) and was obtained by author Neill W. Calvert. Authors Steven P. Burch, Alex Z. Fu, and Thomas R. Thompson are current or former employees of GSK. Calvert and author Penny Reeves were commissioned by GSK specifically for this research.

Calvert served as principal author of the study. Study concept and design were contributed by Calvert and Burch, with input from the coauthors. Data collection was the work of Calvert, Fu, and Reeves, with input from Burch; data interpretation was the work of Calvert, Burch, and Fu, with input from Thompson. Drafting of the manuscript and its revision were primarily the work of Calvert, Burch, and Thompson, with input from the coauthors.

\section{REFERENCES}

1. Goodwin GM. Prophylaxis of bipolar disorder: how and who should we treat in the long term? Eur Neuropsychopharmacol. 1999;9(suppl 4):S125S129

2. Calabrese JR, Shelton MD, Rapport DJ, Kimmel SE. Bipolar disorders and the effectiveness of novel anticonvulsants. J Clin Psychiatry. 2002;63:5-9.

3. Mitchell PB, Mahli GS. The expanding pharmcopoeia for bipolar disorder. Annu Rev Med. 2002;53:173-88.

4. Brambilla P, Barale F, Soares JC. Perspectives on the use of anticonvulsants in the treatment of bipolar disorder. Int J Neuropsychopharmacol. 2001;4: $421-26$

5. Sajatovic M. Bipolar disorder: disease burden. Am J Manag Care. 2005;11 (suppl 3):S80-S84.

6. Akiskal HS, Bourgeois ML, Angst J, Post R, Moller H, Hirschfeld R. Re-evaluating the prevalence of and diagnostic composition within the broad clinical spectrum of bipolar disorders. J Affect Disord. 2000;59(suppl 1):S5-S30.
7. Angst J. The emerging epidemiology of hypomania and bipolar II disorder. J Affect Disord. 1998;50:143-51.

8. Lewinsohn PM, Klein DN, Seeley JR. Bipolar disorders in a community sample of older adolescents: prevalence, phenomenology, comorbidity, and course. J Am Acad Child Adolesc Psychiatry. 1995;34:454-63.

9. Szadoczky E, Papp Z, Vitrai J, Rihmer Z, Furedi J. The prevalence of major depressive and bipolar disorders in Hungary. Results from a national epidemiologic survey. J Affect Disord. 1998;50:153-62.

10. Hirschfeld RM, Calabrese JR, Weissman MM, et al. Screening for bipolar disorder in the community. J Clin Psychiatry. 2003;64:53-9.

11. Wyatt RJ,.Henter I. An economic evaluation of manic-depressive illness1991. Soc Psychiatry Psychiatr Epidemiol. 1995;30:213-19.

12. Begley CE, Annegers JF, Swann AC, et al. The lifetime cost of bipolar disorder in the US: an estimate for new cases in 1998. Pharmacoeconomics. 2001;19:483-95

13. Bowden CL, Calabrese JR, Sachs G, et al. A placebo-controlled 18-month trial of lamotrigine and lithium maintenance treatment in recently manic or hypomanic patients with bipolar I disorder. Arch Gen Psychiatry. 2003;60: 392-400.

14. Calabrese JR, Bowden CL, Sachs G, et al. A placebo-controlled 18-month trial of lamotrigine and lithium maintenance treatment in recently depressed patients with bipolar I disorder. J Clin Psychiatry. 2003;64:1013-24.

15. Tohen M, Bowden CL, Calabrese JR, et al. Olanzapine's efficacy for relapse prevention in bipolar disorder: a randomised double-blind placebo-controlled 12-month clinical trial. Bipolar Disord. February 2004;6(suppl 1):26.

16. Tohen M, Calabrese JR, Sachs GS, et al. Randomized, placebo-controlled trial of olanzapine as maintenance therapy in patients with bipolar I disorder responding to acute treatment with olanzapine. Am J Psychiatry. 2006;163: 247-56.

17. Stang PE, Frank C, Ulcickas Yood M. Bipolar disorder detection, ascertainment, and treatment: primary care physician knowledge, attitudes, and awareness. Primary Care Companion to J Clin Psychiatry. 2006. In press.

18. Brazier J, Roberts J, Deverill M. The estimation of a preference-based measure of health from the SF-36. J Health Econ. 2002;21:271-92.

19. Tengs TO.Wallace A. One thousand health-related quality-of-life estimates Med Care. 2000;38:583-637.

20. Dardennes R, Lafuma A, Watkins S. Prophylactic treatment of mood disorders: cost effectiveness analysis comparing lithium and carbamazepine [article in French]. Encéphale. 1999;25:391-400.

21. Das Gupta R, Guest JF. Annual cost of bipolar disorder to UK society. Br J Psychiatry. 2002;180:227-33.

22. Dilla T, Prieto L, Ciudad A, Sacristan JA. Economic analyses of olanzapine in the treatment of schizophrenia and bipolar disorder [article in Spanish]. Actas Esp Psiquiatr. 2004;32:269-79.

23. National Institute for Health and Clinical Excellence. Technology appraisal guidance 66 . Olanzapine and valproate semisodium in the treatment of acute mania associated with bipolar 1 disorder; 2003. Available at: http://www.nice.org.uk/ download.aspx?o=TA066guidance. Accessed April 26, 2006.

24. National Institute for Health and Clinical Excellence. Guide to the methods of technology appraisal; 2004. Available at: http://www.nice.org.uk/pdf/ TAP_methods.pdf. Accessed March 10, 2006.

25. Calabrese JR, Bowden CL, Findling R, Vieta E. Using mood state to predict polarity of relapse in bipolar maintenance studies. Poster presented at: 44th Annual NCDEU Meeting; June 3, 2005; Boca Raton, FL.

26. Calabrese JR, Vieta E, El-Mallakh R, et al. Mood state at study entry as predictor of the polarity of relapse in bipolar disorder. Biol Psychiatry. 2004;56:957-63.

27. Bridle C, Palmer S, Bagnall AM, et al. A rapid and systematic review and economic evaluation of the clinical and cost-effectiveness of newer drugs for treatment of mania associated with bipolar affective disorder. Health Technol Assess. 2004:8:iii-187. 
28. Huxley NA, Parikh SV, Baldessarini RJ. Effectiveness of psychosocial treatments in bipolar disorder: state of the evidence. Harv Rev Psychiatry. 2000

8:126-40

29. Palmer S, Byford S, Raftery J. Economics notes: types of economic evaluation. BMJ. 1999;318:1349.

30. Briggs A,.Gray A. Using cost effectiveness information. BMJ. 2000;

320:246

31. Keck PE, Nabulsi AA, Taylor JL, et al. A pharmacoeconomic model of divalproex vs. lithium in the acute and prophylactic treatment of bipolar I disorder. J Clin Psychiatry. 1996;57:213-22.
32. Sanderson K, Andrews G, Corry J, Lapsley H. Reducing the burden of affective disorders: is evidence-based health care affordable? J Affect Disord. 2003; $77: 109-25$.

33. Simons WR, Krishnan AA. The economic value of lamotrigine as a mood stabilizer: a U.S. managed care perspective. Manag Care Interface. 2004;17:4449. 